\title{
Left ventricular surgical restoration for anteroseptal scars: Volume versus shape
}

\author{
Antonio M. Calafiore, MD, ${ }^{\mathrm{a}}$ Angela L. Iacò, MD, ${ }^{\mathrm{a}}$ Davide Amata, MD, ${ }^{\mathrm{b}}$ Cataldo Castello, MD, ${ }^{\mathrm{b}}$ \\ Egidio Varone, MD, ${ }^{\mathrm{b}}$ Fabio Falconieri, MD, ${ }^{\mathrm{b}}$ Antonio Bivona, MD, ${ }^{\mathrm{b}}$ Sabina Gallina, MD, ${ }^{\mathrm{c}}$ and \\ Michele Di Mauro, MD $^{\mathrm{d}}$
}

Objective: We report the long-term results of left ventricular surgical restoration in which 2 different strategies were used, which had restoration of ventricular volume or ventricular shape as their target.

\begin{abstract}
Methods: From 1988 to 2008, 308 patients with anterior scars underwent elective left ventricular surgical restoration. Before 2002, a Dor procedure was performed in 107 cases to reduce left ventricular volume (group V); from 1998 to 2001, a Guilmet procedure was performed in 32 patients to rebuild a left ventricular conical shape (group S). From 2002, 169 patients (group S) underwent left ventricular surgical restoration to reshape a conical left ventricle by means of the Dor procedure $(n=29$, septoapical scars) or septal reshaping $(n=140$, when the septum was more involved than the anterior wall). The 2 groups were similar for all features but age, mitral regurgitation grade, mitral valve surgery rate (higher in group S), and ejection fraction (higher in group V).
\end{abstract}

Results: Early mortality was $7.8 \%(11.2 \%$ in group V vs $6.0 \%$ in group $\mathrm{S}, P=.102)$. Logistic regression showed that volume reduction was significantly related to higher early mortality. Five-year cardiac survival, cardiac event-free survival, and event-free survival were higher in group S. Cox analysis showed that the choice of volume reduction provided lower survival (hazard ratio, 2.1), cardiac survival (hazard ratio, 3.0), cardiac event-free survival (hazard ratio, 2.7), and event-free survival (hazard ratio, 2.2). When 30-day events were excluded, volume reduction was still a risk factor for cardiac event-free survival (hazard ratio, 2.2).

Conclusions: When the main target of left ventricular surgical restoration is left ventricular reshaping rather than left ventricular volume reduction, early and late outcomes seem to improve. (J Thorac Cardiovasc Surg 2010;139:1123-30)

Earn CME credits at

http://cme.ctsnetjournals.org

Surgical treatment of anteroseptal scars has been and still is a challenging task for cardiac surgeons. Most patients are in cardiac failure, and the infarcted areas can include different parts of the septum and anterior wall. The core problem of ischemic congestive heart failure is the undue demand put on the residual viable left ventricular (LV) myocardium. ${ }^{1}$ Surgical techniques applied to correct the mismatch between contractile and asynergic areas are different. The most popular one was proposed by Dor and colleagues ${ }^{2,3}$ in the 1980 s

\footnotetext{
From the Department of Adult Cardiac Surgery, ${ }^{\text {a }}$ Prince Sultan Cardiac Center, Riyadh, Kingdom of Saudi Arabia; the Department of Cardiac Surgery, ${ }^{\mathrm{b}}$ University of Catania, Catania, Italy; the Institute of Cardiology, ${ }^{\mathrm{c}}$ University of Chieti, Chieti,

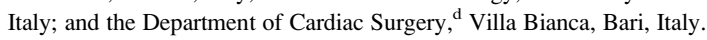

Disclosures: None.

Read at the Eighty-ninth Annual Meeting of The American Association for Thoracic

Surgery, Boston, Mass, May 9-13, 2009.

Received for publication April 29, 2009; revisions received Nov 26, 2009; accepted for publication Jan 2, 2010.

Address for reprints: Antonio M. Calafiore, MD, Department of Adult Cardiac Surgery, Prince Sultan Cardiac Center, Riyadh, Kingdom of Saudi Arabia (E-mail: calafiore@unich.it).

$0022-5223 / \$ 36.00$

Copyright (c) 2010 by The American Association for Thoracic Surgery

doi:10.1016/j.jtcvs.2010.01.001
}

and still is used worldwide. This technique is addressed to the recovery of a predictable volume but not to the rebuilding of a physiologic conical shape. Another French surgeon, Daniel Guilmet, described in the 1980s a technique (overcoat technique) that led to a conical shape of the heart. ${ }^{4}$ We revisited the original Guilmet technique at the end of the 1990s, using some modifications but maintaining the same concept. ${ }^{5}$ In 2002 , we finally applied, in all our patients, techniques finalized to recover a conical shape, septal reshaping, ${ }^{6}$ evolution of the Guilmet technique, and the Dor operation only in the presence of septoapical scars.

The results of the Surgical Treatment for Ischemic Heart Failure (STICH) trial, hypothesis 2, which were recently published, ${ }^{7}$ were not in favor of adding left ventricular surgical remodeling (LVSR) to coronary artery bypass grafting (CABG). However, this study was focused on recovery of volume and not of shape. Furthermore, patients were screened on ejection fraction (EF) and not on ventricular volumes. The purpose of our study is to report the long-term results of 2 different strategies that had, as their targets, restoration of ventricular volume, as in the STICH trial, or of ventricular shape.

\section{MATERIALS AND METHODS Patient Population}

From January 1988 to February 2008, 308 patients underwent first-time surgical exclusion of anteroseptal scars. Two groups could be identified. The 


$$
\begin{aligned}
& \text { Abbreviations and Acronyms } \\
& \text { AMI = acute myocardial infarction } \\
& \mathrm{CABG}=\text { coronary artery bypass grafting } \\
& \mathrm{EF}=\text { ejection fraction } \\
& \mathrm{LV}=\text { left ventricular } \\
& \text { LVSR = left ventricular surgical remodeling } \\
& \text { MR = mitral regurgitation } \\
& \text { NYHA }=\text { New York Heart Association } \\
& \text { STICH }=\text { Surgical Treatment for Ischemic Heart } \\
& \text { Failure }
\end{aligned}
$$

first includes patients in whom the target was LV volume (group V; $\mathrm{n}=107$ patients who had the classic Dor procedure between 1988 and 2001). The second group included patients in whom the target was recovery of LV shape (group $\mathrm{S}, \mathrm{n}=201,32$ patients who had the Guilmet procedure between 1998 and 2001 and 169 who underwent septal reshaping [ $=140]$ or the septoapical Dor procedure [ $n=29]$ between 2002 and February 2008). Retrospective analysis of our database was approved by the institutional review board, which waived patient consent. Table 1 shows some patient characteristics. Echocardiographic transthoracic assessment was performed preoperatively, at discharge from the hospital, and during follow-up.

\section{Echocardiographic Assessment}

In all patients the following data were evaluated: LV systolic and diastolic diameters, LV indexed end-systolic and end-diastolic volumes, EF, and the diastolic sphericity index (transverse diameter/longitudinal diameter). Evaluation of mitral regurgitation (MR) grade integrated multiple parameters (eg, jet area, jet area/left atrial area ratio, number and direction of jets, and vena contracta). MR was divided into 4 grades: mild (1+), moderate (2+), moderate to severe (3+), and severe (4+). Table 1 shows some echocardiographic data from the study groups.

\section{Surgical Techniques}

The Dor procedure (group V) was performed as described by Dor and colleagues. ${ }^{1}$ A rubber balloon inflated with 50 to $60 \mathrm{~mL} / \mathrm{m}^{2}$ saline was used in one third of cases $(\mathrm{n}=37)$. The modified Guilmet procedure (group S) included a suture of the scarred anterior wall to the scarred septum with interrupted U sutures. ${ }^{5}$ Septal reshaping (group $S$ ) was used when the septum was more involved than the anterior wall (Figure $1, A$ ). ${ }^{6}$ In this procedure the length of the patch depends on the distance between the highest point and the new apex; its height is related to the $\mathrm{LV}$ diastolic volume. If less than $80 \mathrm{~mL} / \mathrm{m}^{2}$, the length/height ratio is $2: 1$; if $80 \mathrm{~mL} / \mathrm{m}^{2}$ or greater, the ratio is $3: 1$; and in case of restrictive diastolic dysfunction, the ratio is 3:1 as well. To be sure that the longitudinal diameter is long enough, the position of the new apex has to be roughly $5 \mathrm{~cm}$ from the base of the papillary muscles and, for this purpose, can be positioned in the apical scar. The septoapical Dor procedure (group S) was used only in case of scars that involved the distal portion of the septum and the apex (Figure 1,B). A small patch was used in 11 cases, and in the remaining patients no patch was used. Again, the purse string was positioned roughly $5 \mathrm{~cm}$ from the base of the papillary muscles. Mitral valve surgery was performed in 114 $(37.0 \%)$ cases, $90(45.8 \%)$ in group $\mathrm{S}$ and $24(22.4 \%)$ in group V $(P<.001)$. In $12(3.9 \%)$ cases a mitral prosthesis was inserted inside the native mitral valve because the coaptation depth was greater than 10 $\mathrm{mm},{ }^{8}$ whereas in $102(33.1 \%)$ cases the mitral valve was repaired.

\section{Definition of Terms}

Operative mortality was defined as any death occurring in the first 30 days from surgical intervention and late mortality as any mortality occurring during follow-up. Cardiac death was defined as any death of cardiac cause; patients who experienced sudden or unexplained death were considered as having cardiac death. Cardiac events were defined as cardiac death, cardiac reoperation, hospitalization for heart failure, heart transplantation, and New York Heart Association (NYHA) class III/IV. Any event was defined by the same events, including all deaths of any cause.

\section{Follow-up}

All patients were clinically followed up in our outpatient clinic 3,6, and 12 months after surgical intervention and thereafter at yearly intervals. The most recent information was obtained by calling the patient or the referring cardiologists. Follow-up was $100 \%$ complete. The end of follow-up was June 2008.

\section{Statistical Analysis}

Results are expressed as means \pm standard deviations and median values. Categorical variables were reported as counts and percentages. Differences between the 2 groups were evaluated by means of independent $t$ tests (continuous variables) and $\chi^{2}$ tests (categorical variables). A saturated logistic regression model (Appendix 1) has been used to obtain the propensity score by using group A as a reference (goodness-of-fit c-statistic $=0.81$ ). Different parametric models (exponential, Weibull, and Gompertz) were used to assess changing of hazard function across time; in all cases the hazard risk peaked at 1 month (early phase). Hence risk factors for early mortality were investigated by means of stepwise binary logistic regression, entering into the initial model all variables reported in Appendix 2. The final model was validated bootstrapping 1000 samples, and the results were reported as $\beta$ coefficient \pm standard errors and $P$ values. Five-year survival curves were obtained by using the Kaplan-Meier method; significant difference was evaluated with the log-rank test. Time-to-event analysis was performed by using a multivariable Cox proportional hazard regression (see stepwise logistic regression). The results of Cox analysis were reported as $\beta$ coefficients \pm standard errors and $P$ values. Because surgical experience increased over time during the study period, to eliminate the confounding effect of different early mortality, the events occurring during the first 30 days were eliminated, and the outcome analysis was repeated. Changes in LV volume, sphericity index, and EF from the preoperative period to the follow-up period have been evaluated by means of longitudinal linear mixedmodel regression for repeated measurements. Changes in NYHA class and MR grade across time have been evaluated by means of longitudinal ordinal logistic regression for repeated measurements. ${ }^{9}$ The propensity score was forced in all the regression analyses to adjust all the models for preoperative and operative differences. ${ }^{10}$ Validation of the models was performed in 1000 bootstrap samples. ${ }^{11}$ SPSS software (SPSS, Inc, Chicago, Ill) was used.

\section{RESULTS}

Table 1 shows the clinical, echocardiographic, and surgical data of the 2 groups. All patients had a Q-wave anteroseptal myocardial infarction of differing extent. Operative mortality was $7.8 \%$, higher in group V $(11.2 \%$ vs $6.0 \%)$ but not significantly so $(P=.102)$. Causes of death were cardiac in 19 cases and noncardiac in the remaining 5 cases. Results of stepwise logistic regression are reported in Table 2.

Five-year freedom from death of any cause was $77.6 \% \pm$ $2.5 \%(72.9 \% \pm 4.3 \%$ in group $\mathrm{V}$ vs $81.0 \% \pm 2.9 \%$ in group $\mathrm{S}, P=.140$ ), freedom from cardiac death was $82.5 \% \pm 2.3 \%(76.3 \% \pm 4.1 \%$ vs $86.6 \% \pm 2.6 \%$, $P=.032$; Figure 2, A), freedom from any cardiac event 
TABLE 1. Clinical, echocardiographic, and surgical data

\begin{tabular}{|c|c|c|c|}
\hline & Group V $(\mathbf{n}=107)$ & Group S $(n=201)$ & $P$ value \\
\hline Age (y) & $62 \pm 10$ & $66 \pm 10$ & .001 \\
\hline Female sex & $20(19 \%)$ & $32(16 \%)$ & .536 \\
\hline Angina & $57(53 \%)$ & $108(54 \%)$ & .957 \\
\hline NYHA class & & & .192 \\
\hline II & $49(46 \%)$ & $72(36 \%)$ & \\
\hline III & $42(39 \%)$ & $98(49 \%)$ & \\
\hline IV & $16(15 \%)$ & $31(15 \%)$ & \\
\hline $\operatorname{EDV}\left(\mathrm{mL} / \mathrm{m}^{2}\right)$ & $112 \pm 42$ & $111 \pm 38$ & .811 \\
\hline $\operatorname{ESV}\left(\mathrm{mL} / \mathrm{m}^{2}\right)$ & $73 \pm 33$ & $75 \pm 33$ & .716 \\
\hline $\mathrm{EF}(\%)$ & $39 \pm 10$ & $35 \pm 9$ & $<.001$ \\
\hline $\operatorname{MR}(0-4+)$ & & & $<.001$ \\
\hline 0 & $56(53 \%)$ & $47(23 \%)$ & \\
\hline $1+$ & $24(22 \%)$ & $55(27 \%)$ & \\
\hline $2+$ & $11(10 \%)$ & $56(26 \%)$ & \\
\hline $3+$ & $14(13 \%)$ & $19(10 \%)$ & \\
\hline $4+$ & $2(2 \%)$ & $27(14 \%)$ & \\
\hline TR $(1+-4+)$ & & & $<.001$ \\
\hline 0 & $87(81 \%)$ & $106(53 \%)$ & \\
\hline $1+$ & $16(15 \%)$ & $60(30 \%)$ & \\
\hline $2+$ & $2(2 \%)$ & $24(12 \%)$ & \\
\hline $3+$ & $2(2 \%)$ & $9(4 \%)$ & \\
\hline $4+$ & 0 & $2(1 \%)$ & \\
\hline sPAP (mm Hg) & $35 \pm 11$ & $40 \pm 12$ & $<.001$ \\
\hline Akinesia/dyskinesia & $32 / 75$ & $148 / 53$ & $<.001$ \\
\hline \multicolumn{4}{|l|}{ LVS } \\
\hline Dor & $107(100 \%)$ & $29(14.4 \%)$ & \\
\hline Guilmet & - & $32(15.9 \%)$ & \\
\hline SR & - & $140(69.7 \%)$ & \\
\hline CABG & $97(90.7 \%)$ & $148(73.6 \%)$ & .008 \\
\hline MVS & $24(22.4 \%)$ & $90(45.8 \%)$ & $<.001$ \\
\hline TVS & $4(3.7 \%)$ & $24(11.9 \%)$ & .056 \\
\hline
\end{tabular}

$N Y H A$, New York Heart Association; $E D V$, end-diastolic volume; $E S V$, end-systolic volume; $E F$, ejection fraction; $M R$, mitral regurgitation; $T R$, tricuspid regurgitation, $S P A P$, systolic pulmonary artery pressure; $L V S$, left ventricular surgery; $S R$, septal reshaping; $C A B G$, coronary artery bypass grafting; $M V S$, mitral valve surgery; TVS, tricuspid valve surgery.

was $72.3 \% \pm 2.8 \%(63.9 \% \pm 4.7 \%$ vs $77.9 \% \pm 3.3 \%$, $P=.011$; Figure 2, $B$ ), and freedom from any event was $68.3 \% \pm 2.8 \%(61.7 \% \pm 4.7 \%$ vs $72.7 \% \pm 3.5 \%$, $P=.052)$. After a mean of $46 \pm 43$ months, $58(18.8 \%)$ patients died (28 in group $\mathrm{V}$ and 30 in group $\mathrm{S}$ ) of cardiac causes in 44 cases and noncardiac causes in 14 cases. During the follow-up period, 6 patients underwent heart transplantation after a mean of $25 \pm 18$ months; other cardiac reoperations were performed in 5 patients (reoperation for recurrence of $\mathrm{MR}$ in 1 , reoperation to relieve untreated MR in 3, and implantation of a ventricular assist device in 1). Hospitalization for heart failure occurred in 48 patients (19 in group S and 29 in group V). Cox analysis, adjusted for propensity score, showed that the choice of volume rather than shape was a risk factor for late death of any cause, cardiac death, a cardiac event, and any event (Table 2). Excluding first-month events, freedom from death of any cause was $84.2 \%(82.1 \%$ in group $\mathrm{V}$ vs $86.2 \%$ in group $\mathrm{S}$,
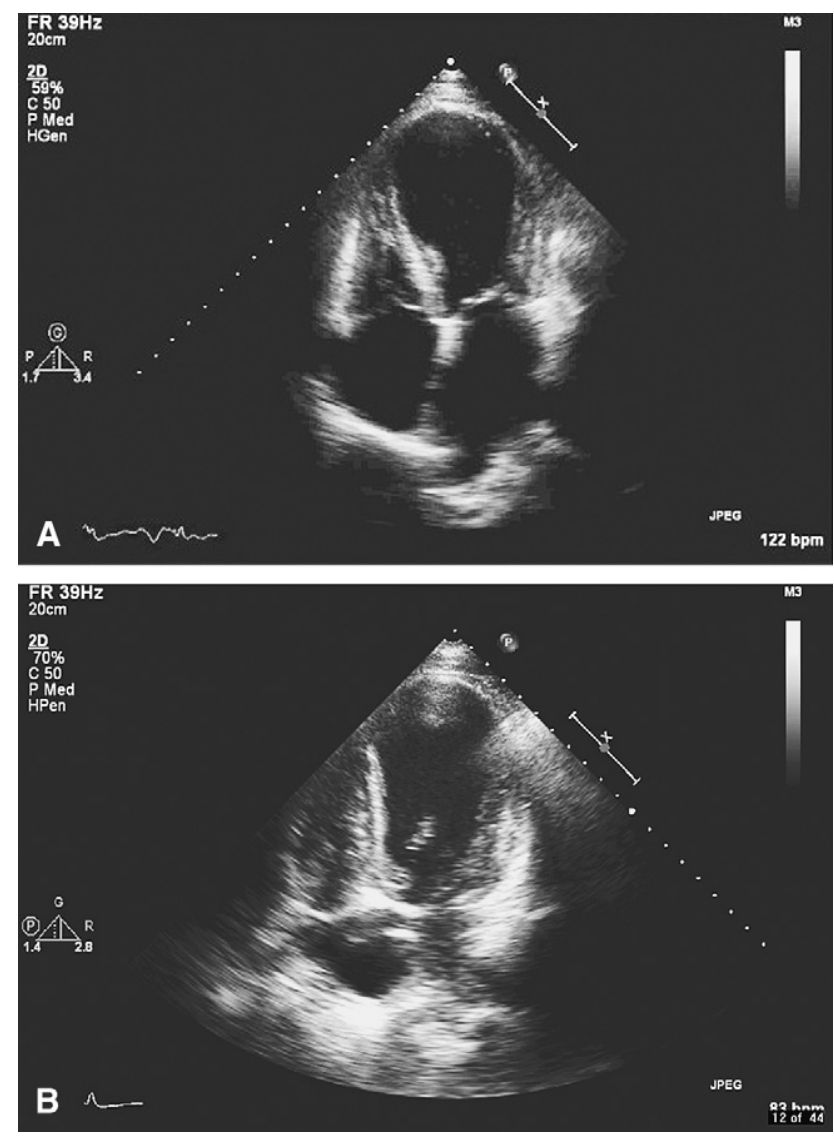

FIGURE 1. Transthoracic echocardiographic analysis, 4 chambers. A, The scar involves the septum and the apex. B, The scar is limited to the septoapical portion of the left ventricle.

$P=.528)$, freedom from cardiac death was $87.9 \%$ (85.1\% in group V vs $90.2 \%$ in group $\mathrm{S}, P=.300)$, freedom from cardiac events was $77.1 \%(71.2 \%$ in group $\mathrm{V}$ vs $81.1 \%$ in group $\mathrm{S}, P=.039)$, and freedom from any event was $77.1 \%(69.5 \%$ in group $\mathrm{V}$ vs $77.4 \%$ in group $\mathrm{S}$, $P=.211)$. Cox analysis, adjusted for age, $\mathrm{EF}$, and mitral valve surgery, confirmed that the choice of volume rather than the shape was a risk factor for freedom from cardiac events (hazard ratio, 2.2; 95\% CI, 1.2-3.8; $P=.007$ ).

At the end of the follow-up period, 222 patients survived, with a mean follow-up of $77 \pm 50$ months. Among them, 190 $(85.6 \%)$ were in NYHA class I or II $(77.6 \%$ in group $\mathrm{V}$ and $89.1 \%$ in group $\mathrm{S})$. LV reshaping rather than volume reduction was associated with NYHA class improving across time (coefficient, $-0.82 \pm 0.25 ; P=.001$ ); patients with lower preoperative NYHA class showed higher probability to remain unchanged or improved $(0.34 \pm 0.13, P=.007)$.

A postoperative echocardiogram was obtained in 125 patients within 10 years from surgical intervention (Table 3). The choice of ventricular reshaping rather than reduction ( $\beta$ coefficient \pm standard error, $14.8 \pm 7.7 ; P=.020)$ and lower preoperative EF ( $\beta$ coefficient \pm standard error, -0.6 

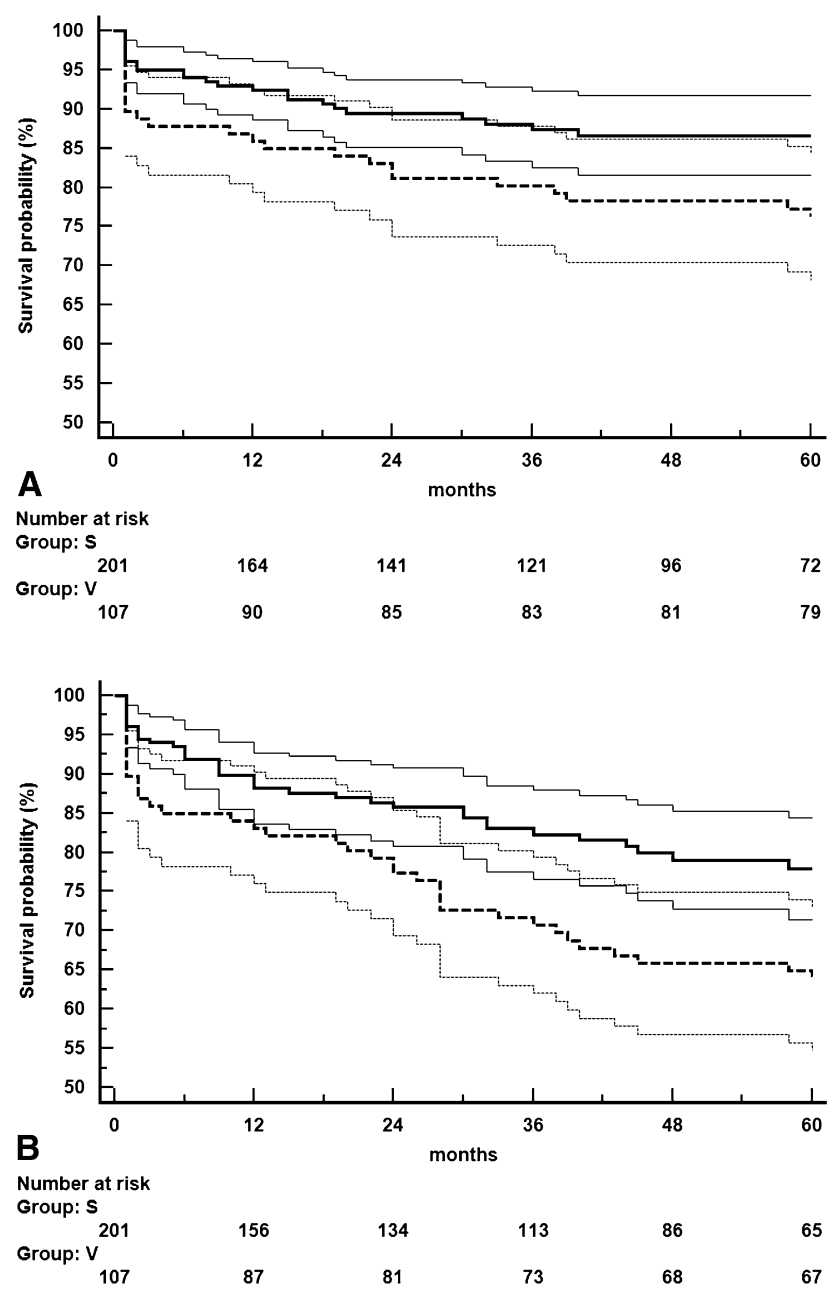

FIGURE 2. Kaplan-Meier curves: 5 -year freedom from cardiac death (A) and freedom from cardiac events (B). The solid line represents group S, and the dashed line represents group V. Patients at risk and $95 \%$ confidence limits are also reported.

$\pm 0.09, P<.001)$ were found to be associated with EF improving across time. No factors were found to be associated with LV volume increase, sphericity index improvement, and MR impairment across time.

\section{DISCUSSION}

The main findings of this study were the following: (1) long-term outcome after LVSR is good, independently from the surgical technique used, and (2) when shape, and not volume, is the goal of LVSR, 5-year results are uniformly better. The evolution of surgical techniques for LVSR is still in progress. Since the early 1980s, Dor and colleagues ${ }^{2,3}$ described a technique that deeply influenced the history of treatment of postischemic congestive heart failure. With some modifications, it is still a standard of care in this field. Menicanti and coworkers ${ }^{12}$ introduced the use of a shaper to the classic Dor technique to change the philoso-
TABLE 2. Stepwise logistic regression and Cox analysis, adjusted for propensity score

\begin{tabular}{lcr}
\hline & $\beta$ coefficient \pm SE & $\boldsymbol{P}$ value \\
\hline 30-d mortality & & \\
LV volume reduction & $1.1 \pm 0.5$ & .038 \\
MVS & $1.2 \pm 0.5$ & .019 \\
Age & $0.07 \pm 0.03$ & .032 \\
NYHA class & $1.1 \pm 0.4$ & .001 \\
5-y any death & & \\
LV volume reduction & $0.9 \pm 0.3$ & .003 \\
MVS & $1.1 \pm 0.3$ & .001 \\
5-y cardiac death & $1.0 \pm 0.3$ & .003 \\
LV volume reduction & $1.3 \pm 0.3$ & $<.001$ \\
MVS & & .001 \\
5-y cardiac event & $1.0 \pm 0.3$ & $<.001$ \\
LV volume reduction & $1.3 \pm 0.3$ & .001 \\
MVS & & $<.001$ \\
5-y any event & $0.9 \pm 0.3$ & \\
LV volume reduction & $1.1 \pm 0.2$ & \\
MVS &
\end{tabular}

$S E$, Standard error; $L V$, left ventricular; $M V S$, mitral valve surgery; $N Y H A$, New York Heart Association.

phy from the pure search for an adequate volume to the recovery of a cavity that is as conical as possible. This goal was also the purpose of the overcoat technique, described by Guilmet and associates in $1984,{ }^{4}$ which elegantly rebuilt a conical cavity by suturing the anterior wall directly to the scarred septum. Need for a more physiologic shape goes together with the changing pattern of septoapical scars. In the past, dyskinetic areas and dilation were predominant, and volume reduction was relatively easy to perform. More recently, akinesia became the most diffuse morphologic aspect. In our experience akinetic areas are present in more than $70 \%$ of the patients who undergo LVR. However, these patients present worse hemodynamic parameters with lower LV compliance. Reduction of distensibility increases the end-diastolic pressures (and, consequently, the pulmonary pressures) and affects the remote zones earlier than in patients with dyskinetic areas. When progressive dilation of the uninvolved zone becomes predominant and dilated cardiomyopathy occurs, medical treatment and surgical options, except for heart transplantation, become ineffective and temporary. ${ }^{13}$ The extent of the dilation is often not uniform. The involvement of the septum and anterior free wall is often different because of the anatomy of the branches of the left anterior descending coronary artery. Diagonal branches originate often at $45^{\circ}$; as a consequence, the involvement of the anterior free wall is triangular, with the apex in the upper portion. Septal branches originate often at $70^{\circ}$ to $90^{\circ}$; as a consequence, the involvement of the septum starts as high as the anterior free wall but is deeper than it. The septum then bulges toward the right ventricle, minimizing the external dilation (Figure 1, $A$ ). This anatomic aspect has become frequent ( $82.8 \%$ of the cases since 2002$)$, 
TABLE 3. Echocardiographic results

\begin{tabular}{|c|c|c|c|c|c|c|}
\hline & \multicolumn{2}{|c|}{ All } & \multicolumn{2}{|c|}{ Group V } & \multicolumn{2}{|c|}{ Group S } \\
\hline & Pre $(n=125)$ & Post $(n=125)$ & Pre $(n=44)$ & Post $(n=44)$ & Pre $(n=81)$ & Post $(n=81)$ \\
\hline $\operatorname{EDV}\left(\mathrm{mL} / \mathrm{m}^{2}\right)$ & $110 \pm 36$ & $86 \pm 27$ & $105 \pm 34$ & $88 \pm 29$ & $112 \pm 37$ & $86 \pm 26$ \\
\hline $\mathrm{EDV} \Delta \% *$ & & $-24(-37 /-11)$ & & $-20(-7 / 57)$ & & $-28(-35 / 0)$ \\
\hline $\operatorname{ESV}\left(\mathrm{mL} / \mathrm{m}^{2}\right)$ & $74 \pm 34$ & $52 \pm 22$ & $67 \pm 28$ & $52 \pm 19$ & $76 \pm 35$ & $53 \pm 22$ \\
\hline ESV $\Delta \% *$ & & $-24(-50 / 0)$ & & $-18(-56 /-10)$ & & $-30(-48 / 0)$ \\
\hline $\mathrm{EF}(\%)$ & $36 \pm 11$ & $41 \pm 11$ & $39 \pm 11$ & $41 \pm 10$ & $33 \pm 10$ & $41 \pm 12$ \\
\hline $\mathrm{EF} \Delta \% *$ & & $16.1(-2.9 / 35.9)$ & & $7.8(-9.5 / 23.6)$ & & $17.1(0 / 42.4)$ \\
\hline SI & $0.69 \pm 0.10$ & $0.71 \pm 0.13$ & $0.69 \pm 0.10$ & $0.75 \pm 0.13$ & $0.69 \pm 0.10$ & $0.69 \pm 0.13$ \\
\hline MR & $1.5 \pm 1.2$ & $0.7 \pm 0.7$ & $1.0 \pm 0.9$ & $0.6 \pm 0.6$ & $1.8 \pm 1.1$ & $0.7 \pm 0.6$ \\
\hline Follow-up (mo) & & $47 \pm 29(12-110)$ & & $50 \pm 32(16-110)$ & & $46 \pm 28(12-107)$ \\
\hline
\end{tabular}

Pre, Preoperative; Post, postoperative; $E D V$, end-diastolic volume; $E S V$, end-systolic volume; $E F$, ejection fraction; $S I$, sphericity index; $M R$, mitral regurgitation. *Data are expressed as median values and quartiles.

and the purpose of septal reshaping, as proposed by us in 2004 , is to address the correction mainly to the septum, which is rebuilt in such a way to be moved anteriorly; the longitudinal axis is maintained as long as possible to maintain a conical shape. ${ }^{6}$ This technique is an evolution of the Guilmet procedure, which we revisited, with some modifications, in the late 1990s and used until 2001. ${ }^{5}$ However, when the scar is limited to the apical portion of the septum and the anterior wall, a classic Dor procedure with or without a patch will guarantee the maintenance of the conical shape because it is applied to the distal part of the LV. The other peculiar aspect of this disease is the progressive increase in MR incidence: in group $\mathrm{S} 45.8 \%$ of the patients required mitral valve surgery versus $22.4 \%$ in group V. Conventional goals during reconstruction of the left ventricle in patients with ischemic heart disease and anteroseptal scars are directed toward excluding scars. However, retention of the spherical shape might persist when patch placement is limited to the scar rim (see Figure 4 in Doenst and coworkers ${ }^{14}$ ); the result is a smaller cavity and a more spherical heart. LV sphericity can further progress in the months after surgical intervention. ${ }^{15}$ Fluid dynamics in more spherical ventricles are impaired, ${ }^{14}$ and reduction of both volume and wall stress can be insufficient to improve function. ${ }^{16}$ Our study shows that when the shape is the goal of the LV surgery, results are superior not only in the early term but also in the long term. Need for a different surgical strategy is emphasized by the results of the STITCH trial, hypothesis $2,{ }^{7}$ which reports the data from 1000 patients randomized for CABG $(\mathrm{n}=499)$ or CABG and LVSR $(\mathrm{n}=501)$. This study failed to show any benefit of LVSR when compared with similar patients in whom only CABG was performed in terms of mortality, both early and late, and heart failure hospitalization. Both groups had equal improvement in Canadian Cardiovascular Society angina class, in NYHA heart failure class, in 6-minute walking test results, and, globally, in symptoms. The surgical technique used was the classic Dor operation, ${ }^{17,18}$ in which the purpose was to re-establish a volume and not a shape. Strangely, the presence of a previ- ous acute myocardial infarction (AMI) was not a prerequisite for study inclusion $(13 \%$ of the patients in each group had no AMI), and whether a previous AMI was Q-wave or no Q-wave was not specified. Recently, Carluccio and colleagues ${ }^{19}$ showed that in patients with an EF of less than $40 \%$ and no evidence of transmural AMI, the presence of hybernating myocardium could cause severe geometric modifications, which can mimic a septoapical scar (see Figure 5, $B$, in Carluccio and colleagues ${ }^{19}$ ) but are reversible after $\mathrm{CABG}$ alone. The success of $\mathrm{LV}$ remodeling surgery depends on how it affects end-systolic pressure-volume (elastance) and end-diastolic pressure-volume (compliance) relationships and how these changes affect ventricular function (stroke volume versus end-diastolic pressure [Starling] relationship) ${ }^{20}$ The effect of surgical intervention on the Starling relationship remains unclear because many patients have simultaneous $\mathrm{CABG}$ or $\mathrm{CABG}$ and mitral valve surgery. This makes the clinical effect of LVSR on LV function impossible to interpret. Furthermore, diastolic function after LVSR depends also on the amount of fibrous tissue present in the remote area. Takeda and coworkers ${ }^{21}$ demonstrated that the percentage of fibrosis detected with nuclear magnetic resonance imaging correlated linearly with significantly worse postoperative hemodynamic variables and LV function recovery. Most of the patients in our recent experience (group S) had akinetic rather than dyskinetic areas. Akinesia was a risk factor in some reports; however, in our experience patients with akinetic anteroseptal segments had similar results to patients with dyskinetic areas. A limit of any procedure that aims for left ventricular reshaping is the preoperative diastolic dimension of the base of the heart, ${ }^{22}$ a surrogate that reflects changes toward sphericalization of the left ventricle. This results in change of the myofibril orientation from oblique to transverse, and this disposition is caused by the loss of elliptical shape and results in a diminished function, which in turn causes more enlargement with deeper geometric (spherical) consequence. When LVSR has to be abandoned in favor of different treatments (LV mechanical support and heart transplantation) is still matter of debate. 


\section{Limitations of the Study}

This study has several limitations. It is a retrospective analysis of many patients undergoing operations over a long period of time, when techniques, strategies, and experience progressively increased and improved, and the retrospective nature of this study causes, by definition, a selection bias. Moreover, this article reports the evolution of a concept across time, starting from the volume reduction to LV reshaping, and therefore although its retrospective nature represents a limitation, we believe that a retrospective study is the only chance we had to report our experience. Being retrospective, some preoperative data are missing (ie, wall motion data, right ventricular function, description of any coronary lesion, and conicity index) or incomplete, and therefore a complete vision of the preoperative status of the patients was not possible in some cases. Furthermore, the echocardiographic assessment was possible in only $45 \%$ of the patients. We were not able to confirm that this new surgical technique resulted in a different ventricle than the previous surgical technique used by us late after surgical intervention because we did not have a consistent echocardiographic follow-up.

Most descriptions of the effect of shape on function are only experimental or rely on assumptions never validated in human diseased hearts. The notion that myofibril orientation changes within a remote segment of myocardium with the development of dilation in response to an anterior infarction has never been demonstrated in vivo. ${ }^{14}$

\section{CONCLUSION}

Long-term results after LVSR are satisfying but in our experience seem to be better if a conical shape is rebuilt. The designation of $\mathrm{V}$ and $\mathrm{S}$ groups represents different patient groups, and the more recent group fared better than the early group. Future studies will be required to determine whether the attempt to reshape the ventricle was successful and influenced the outcome. An unsolved question is how to establish the limits of LVSR (eg, grade of preoperative diastolic dysfunction, diastolic diameter, ventricular volume, and function of the remote zone). The role of each treatment for the single patient (medical treatment, $\mathrm{CABG}$ alone, and CABG and LVSR) is still to be identified.

\section{References}

1. Dor V, Civaia F, Alexandrescu C, Montiglio F. The post-myocardial infarction scarred ventricle and congestive heart failure: the preeminence of magnetic resonance imaging for preoperative, intraoperative, and postoperative assessment. $J$ Thorac Cardiovasc Surg. 2008;136:1405-12.

2. Dor V, Kreitmann P, Jourdan J, Acar C, Saab M, Coste P, et al. Interest of physiological closure (circumferential plasty on contractive areas) of left ventricle after resection and endocardectomy for aneurysm or akinetic zone comparison with classical technique about a series of 209 left ventricular resections [abstract]. $J$ Cardiovasc Surg. 1985;26:73.

3. Dor V, Saab M, Coste P, Kornaszewska M, Montiglio F. Left ventricular aneurysm: a new surgical approach. J Thorac Cardiovasc Surg. 1989;37:11-9.

4. Guilmet D, Popoff G, Dubois C, Tawil N, Bachet J, Goudot B, et al. Nouvelle technique chirurgicale pour la cure des aneurysmes du ventricule gauche: l'aneur- ysmoplastie en paletot. Resultats preliminaires. 11 observations. Arch Mal Coeur Vaiss. 1984;77:953-8.

5. Calafiore AM, Gallina S, Di Mauro M, Pano M, Teodori G, Di Giammarco G, et al. Left ventricular aneurysmectomy: endoventricular circular patch plasty or septoexclusion. J Cardiac Surg. 2003;18:93-100.

6. Calafiore AM, Mauro MD, Di Giammarco G, Gallina S, Iaco AL, Contini M, et al. Septal reshaping for exclusion of anteroseptal dyskinetic or akinetic areas. Ann Thorac Surg. 2004; 77:2115-21.

7. Jones RH, Velazquez EJ, Michler RE, Sopko G, Oh JH, O'Connor CM, et al. Coronary bypass surgery with or without surgical ventricular reconstruction. $N$ Engl J Med. 2009;360:1705-17.

8. Calafiore AM, Gallina S, Di Mauro M, Gaeta F, Iacò AL, D'Alessandro S, et al. Mitral valve procedure in dilated cardiomyopathy: repair or replacement? Ann Thorac Surg. 2001;71:1146-53.

9. Diggle DJ, Liang KY, Zega SL. Analysis of longitudinal data. Oxford (NY): Oxford Science Publications; 1994.

10. Blackstone E. Comparing apples and oranges. J Thorac Cardiovasc Surg. 2002; 123:8-15.

11. Austin P, Tu J. Bootstrap methods for developing predictive models in cardiovascular research. Am Stat. 2004;58:131-7.

12. Menicanti L, Castelvecchio S, Ranucci M, Frigiola A, Santambrogio C, de Vincentiis C, et al. Surgical therapy for ischemic heart failure: single-center experience with surgical anterior ventricular restoration. J Thorac Cardiovasc Surg. 2007; 134:433-41.

13. Sartipy U, Albåge A, Lindblom D. Risk factors for mortality and hospital re-admission after surgical ventricular restoration. Eur J Cardiothorac Surg. 2006;30: 762-9.

14. Doenst T, Spiegel K, Reik M, Markl M, Hennig J, Nitzsche S, et al. Fluid-dynamic modeling of the human left ventricle: methodology and application to surgical ventricular reconstruction. Ann Thorac Surg. 2009;87:1187-95.

15. Ueno T, Sakata R, Iguro Y, Yamamoto H, Ueno M, Ueno T, et al. Mid-term changes of left ventricular geometry and function after Dor, SAVE, and overlapping procedures. Eur J Cardiothorac Surg. 2007;32:52-7.

16. Dang ABC, Guccione JM, Zhang P, Wallace AW, Gorman RC, Gorman JH III, et al. Effect of ventricular size and patch stiffness in surgical anterior ventricular restoration: a finite element model study. Ann Thorac Surg. 2005;79: 185-93.

17. Athanasuleas CL, Stanley AWH Jr, Buckberg GD, Dor V, Di Donato M, Blackstone EH. Surgical anterior ventricular endocardial restoration (SAVER) in the dilated remodeled ventricle after anterior myocardial infarction. $J \mathrm{Am}$ Coll Cardiol. 2001;37:1199-209.

18. Eisen HJ. Surgical ventricular reconstruction for heart failure. $N$ Engl J Med. 2009;360:1781-4

19. Carluccio E, Biagioli P, Alunni G, Murrone A, Giombolini C, Ragni T, et al. Patients with hibernating myocardium show altered left ventricular volumes and shape, which revert after revascularization evidence that dyssynergy might directly induce cardiac remodeling. J Am Coll Cardiol. 2006;47: 969-77.

20. Ratcliffe MB, Hong J, Salahieh A, Ruch S, Wallace AW. The effect of ventricular volume reduction surgery in the dilated, poorly contractile left ventricle: a simple finite element analysis. J Thorac Cardiovasc Surg. 1998;116:566-77.

21. Takeda K, Matsumiya G, Matsue H, Hamada S, Sakaki M, Sakaguchi T, et al. Use of quantitative analysis of remote myocardial fibrosis with delayed-enhancement magnetic resonance imaging to predict outcomes after surgical ventricular restoration for ischemic cardiomyopathy. J Thorac Cardiovasc Surg. 2008;136: 1514-21.

22. Ferrazzi P, Matteucci MLS, Merlo M, Iacovoni A, Rescigno G, Bottai N, et al. Surgical ventricular reverse remodeling in severe ischemic dilated cardiomyopathy: the relevance of the left ventricular equator as a prognostic factor. $J$ Thorac Cardiovasc Surg. 2006;131:357-63.

\section{Discussion}

Dr Lorenzo A. Menicanti (Milan, Italy). I have no conflict of interest.

I want to congratulate Antonio for this very interesting presentation. It is an important effort to improve our knowledge in a very unique surgical field, particularly when the data of the STICH trial have been published, raising a lot of discussion. Before considering 
the core of this presentation, it is correct in my mind to define the surgical procedure named the Dor procedure. Considering this procedure, as it has been done in Antonio's presentation, as simple volumetric reduction is reductive and shows a limited knowledge of the Dor procedure's contribution. In the original article Dor published in 1988, the procedure is described as "endoventricular circular patch plasty with septal exclusion." The goal, as described in this article, is exclusion of the septal akinetic segment, reorganizing the remaining LV muscle without critically compromising the size of the left ventricle. Therefore this technique deeply affects the septal reshaping. Today, a series of new techniques have been published for surgical ventricular restoring, but the basic concept is always the same as defined by Vincent Dor, even if people have some difficulties admitting it.

In this article Dr Calafiore proposes a surgical technique to preserve as much as possible an elliptical shape, and the results are compared with those of a surgical technique defined as the standard Dor procedure. I have 3 questions for Antonio.

First, according to your procedure, the length of the patch depends on the distance between the highest point and the new apex. How do you select the position of the new apex when the entire apical zone is involved in LV dilatation and the longitudinal diameter is elongated?

Dr Calafiore. Thank you, Lorenzo, for your questions. In the normal heart the longitudinal diameter is made by 2 parts. The first one goes from the base of the heart to the base of the papillary muscles; this part cannot be treated by means of surgical intervention. The second part goes from the base of the papillary muscles to the apex; this segment is approachable during surgical intervention.

In the normal heart the transverse diameter is roughly similar to the distance from the base of the heart to the base of the papillary muscle. The second distance is around $3 \mathrm{~cm}$. When we have to choose a new apex in patients with a transverse diameter larger than normal, the new apex has to be positioned at least $5 \mathrm{~cm}$ from the base of the papillary muscles, depending on the transverse diameter and on the fixed part of the longitudinal diameter (base of the heart-base of the papillary muscles). This allows us to maintain an acceptable sphericity index. If the scar is near the papillary muscle, the apex has to be in the scarred part. Then we need to include the scar in the correction.

Dr Menicanti. Thank you. You conclude in your article that a more physiologic elliptical shape improves the surgical results. Unfortunately, as you say, the 2 groups of patients underwent operations in 2 different periods. The 2 groups had the same baseline volume, but the reduction of the volume was different; $30 \%$ was the reduction in group S against only $20 \%$ in group V. The EF increased in $17 \%$ in group $S$ against 7 in group V. CABG was performed in $73 \%$ of group $\mathrm{S}$ versus $9 \%$ of group $\mathrm{V}$.
It seems to me that the group $\mathrm{V}$ patients had a more diffuse disease than the group $\mathrm{S}$ patients, in whom a more localized dilatation is present with a better contractility in the remote zone. This can explain a good improvement of EF with fewer revascularizations. Therefore the better result can be linked to a more important volume reduction in the shape group. Can you comment on that?

Dr Calafiore. The volume reduction shown in the slides is the volume reduction after roughly 5 years and not in the immediate postoperative period. The difference in revascularization depends on different surgical strategies. In the beginning, the left anterior descending coronary artery was always grafted, even if the territory was scarred. Today we never graft the left anterior descending coronary artery if its territory is extensively scarred. The clinical pattern of the patients we see today is worse than before because the presence of akinetic areas with higher pulmonary pressures reflects a clinical status in these patients that is worse than before. In the past, surgical intervention was easier because the areas were mainly dyskinetic. Today these patients are sicker than before because the akinetic areas are predominant.

Dr Menicanti. Finally, If the goal of the procedure is to exclude all scars from the cavity, keeping a sphericity index in the normal range, how do you avoid the risk of having too small a cavity at the end of the procedure?

Dr Calafiore. The purpose of the correction is not to totally eliminate the scar. You cannot completely eliminate the scar while maintaining a conical heart. To avoid the excess or reduction of volume, we modify not the length of the patch, which depends on the position of the new apex, but its height, which depends on the initial end diastolic volume. In the presence of large end-diastolic volumes $\left(\geq 80 \mathrm{~mL} / \mathrm{m}^{2}\right)$, we use a patch with a length/height ratio of $3: 1$. If the end-diastolic volume is less than $80 \mathrm{~mL} / \mathrm{m}^{2}$, we use a larger patch with a ratio of 2:1. This strategy eliminates or reduces at the maximum the possibility of a hypodiastolic syndrome.

Dr Menicanti. But this is determined by your experience?

Dr Calafiore. Of course.

Dr Menicanti. There are no rules?

Dr Calafiore. The only rule we follow is that the apex has to be put in the scarred tissue to have a longitudinal diameter that is as long as possible. Patients with apical akinesia can have a normal life if the akinesia is concentrated just in the distal portion of the left ventricle. We then prefer to have some scarring in the apex rather than to eliminate all the scars but with the danger of having a small cavity with a sphericity index that can approach 1.0.

Dr Menicanti. Do you think that is the approach with your experience?

Dr Calafiore. I think so. I am not the only surgeon who is using this technique.

Dr Menicanti. Thank you very much. 
APPENDIX 1. Variables building the final propensity score model

Age

Female sex

Location of myocardial infarction

Angina

New York Heart Association class

Ejection fraction

End-systolic volume

Reoperation

Mitral regurgitation

Tricuspid regurgitation

Systolic pulmonary artery pressure

Mitral valve surgery

Tricuspid valve repair

Number of grafts
APPENDIX 2. Variables initially entered into the multivariable models

Age (years)

Sex

Body mass index

Body surface area

New York Heart Association class

Heart failure

Angina

Chronic atrial fibrillation

Presence of diabetes

Presence of hypertension

Presence of hypercholesterolemia

The location of myocardial infarction

Presence of dyskinesis versus akinesis

Chronic obstructive pulmonary disease

Chronic renal failure

Extracardiac vasculopathy/previous stroke or transient ischemic attack

Left ventricular end-diastolic volume $\left(\mathrm{mL} / \mathrm{m}^{2}\right)$

Left ventricular end-systolic volume $\left(\mathrm{mL} / \mathrm{m}^{2}\right)$

Left ventricular ejection fraction $(\%)$

Left ventricular end-diastolic sphericity index

Mitral regurgitation grade (from 0 to $4+$ )

Tricuspid regurgitation grade (from 0 to $4+$ )

Systolic pulmonary artery pressure $(\mathrm{mm} \mathrm{Hg})$

Mitral valve surgery

Coronary artery bypass grafting

Tricuspid valve surgery

Surgical choice of volume reduction rather than reshaping

Reoperation

Cardiopulmonary bypass time (min)

Cross-clamping time (min)

Surgeon

Year of operation

Time interval (distance from follow-up to operation time in months)*

*Time interval was initially inserted into the longitudinal regression analyses (both mixed and ordinal). 